\title{
Perinatal outcome of fetuses with congenital high airway obstruction syndrome: a single-center experience
}

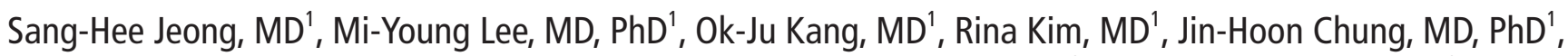
Hye-Sung Won, MD, PhD', Pil-Ryang Lee, MD, PhD', Euiseok Jung, MD, PhD², Byong Sop Lee, MD, PhD², Woo-Jong Choi, MD, $\mathrm{PhD}^{3}$, Yoon Se Lee, MD, $\mathrm{PhD}^{4}$

${ }^{1}$ Department of Obstetrics and Gynecology, ${ }^{2}$ Division of Neonatology, Department of Pediatrics, Departments of ${ }^{3}$ Anaesthesiology and Pain Medicine, ${ }^{4}$ Otolaryngology, Asan Medical Center, University of Ulsan College of Medicine, Seoul, Korea

\section{Objective}

To report our experience with management of fetuses with congenital high airway obstruction syndrome (CHAOS).

\section{Methods}

We retrospectively reviewed the cases of fetuses who were prenatally diagnosed and postnatally confirmed with CHAOS between 2010 and 2019 at Asan Medical Center, Seoul, Korea.

Results

Of 13 fetuses prenatally diagnosed with CHAOS, 7 were lost to follow-up and 6 were postnatally confirmed as having CHAOS. All fetuses, except one were delivered via cesarean section with an ex utero intrapartum treatment (EXIT) procedure. Two patients had coexisting congenital heart diseases requiring several cardiac surgeries following birth. Both of these patients demonstrated developmental delay; however, the remaining 4 had a normal development except for expressive language. Two infants died of respiratory complications, and the remaining 4 were alive at the end of the follow-up period. All 4 live patients underwent tracheostomy with planned reconstruction surgery. Three children are now able to phonate, and 1 can maintain a conservation.

\section{Conclusion}

The proper management of CHAOS using the EXIT procedure results in high survival and low hypoxemia-induced complication rates. Therefore, an accurate prenatal diagnosis is necessary for an appropriate perinatal management.

Keywords: Airway obstruction; Laryngeal disease; Prenatal diagnosis; Tracheostomy

\section{Introduction}

Congenital high airway obstruction syndrome (CHAOS) is a rare and fatal malformation that can lead to death immediately after birth, especially if not diagnosed prenatally [1]. CHAOS is caused by deficient recanalization of the upper respiratory tract at around 10 weeks of gestation [1]. Upper airway obstruction blocks the flow of fetal lung fluid, which results in an expansion of the airway and lungs. An increased intrathoracic pressure resulting from the aforementioned blockage impairs venous return and cardiac function [2]. The typical prenatal ultrasonographic findings of CHAOS include symmetrically enlarged echogenic lungs, a flattened or inverted diaphragm, dilated airways, and an anteriorly displaced heart [1]. CHAOS can be associated with several
Received: 2020.09.04. Revised: 2020.10.15. Accepted: 2020.10.21.

Corresponding author: Mi-Young Lee, MD, PhD

Department of Obstetrics and Gynecology, Asan Medical Center,

University of Ulsan College of Medicine, 88 Olympic-ro 43-gil,

Songpa-gu, Seoul 05505, Korea

E-mail: poptwinkle@hanmail.net

https://orcid.org/0000-0003-2691-4954

Pil-Ryang Lee has been an Editorial Board of Obstetrics \& Gynecology Science; however, he was not involved in the peer reviewer selection, evaluation, or decision process of this article. Otherwise, no other potential conflicts of interest relevant to this article was reported.

Articles published in Obstet Gynecol Sci are open-access, distributed under the terms of the Creative Commons Attribution Non-Commercial License (http://creativecommons. org/licenses/by-nc/3.0/) which permits unrestricted non-commercial use, distribution, and reproduction in any medium, provided the original work is properly cited.

Copyright $\odot 2021$ Korean Society of Obstetrics and Gynecology 


\section{Obstetrics \& Gynecology Science}

Sang-Hee Jeong, et al. Congenital high airway obstruction

syndromes, such as Fraser, cri du chat, short-rib polydactyly, and 22 q11.2 deletion syndromes $[3,4]$.

Recently, ultrasonography and magnetic resonance imaging (MRI) have enabled the diagnosis of CHAOS in the prenatal period. Morbidity and mortality have been reduced by the development of the ex utero intrapartum treatment (EXIT) procedure through intubation or tracheostomy while maintaining fetal circulation [5-10]. However, due to the rarity of the disease, only a few cases of CHAOS have been reported describing the postnatal management and long-term prognosis $[11,12]$. The purpose of this study was to report our experience in CHAOS management, and to discuss the longterm postnatal outcomes of infants prenatally diagnosed with CHAOS by reviewing previously published articles.
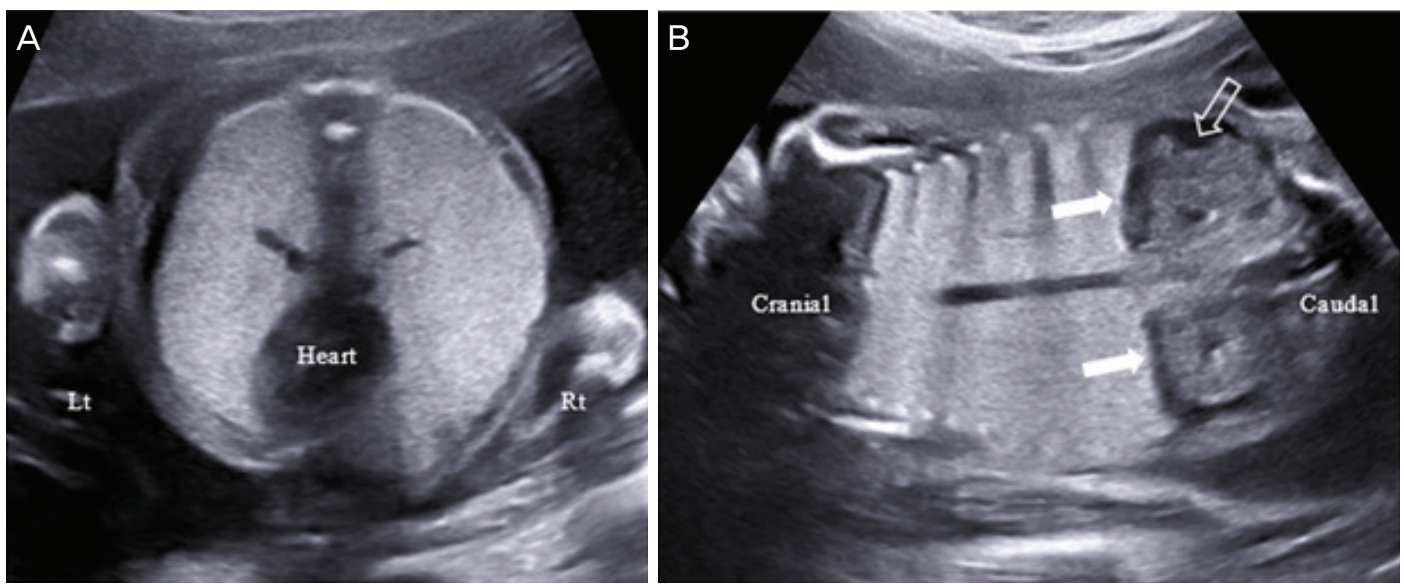

Fig. 1. Prenatal ultrasonography showing symmetrically enlarged, hyperechoic, and homogeneous lungs with centrally positioned heart (A), flatted diaphragm (solid arrows in B), and associated ascites (open arrow in B).
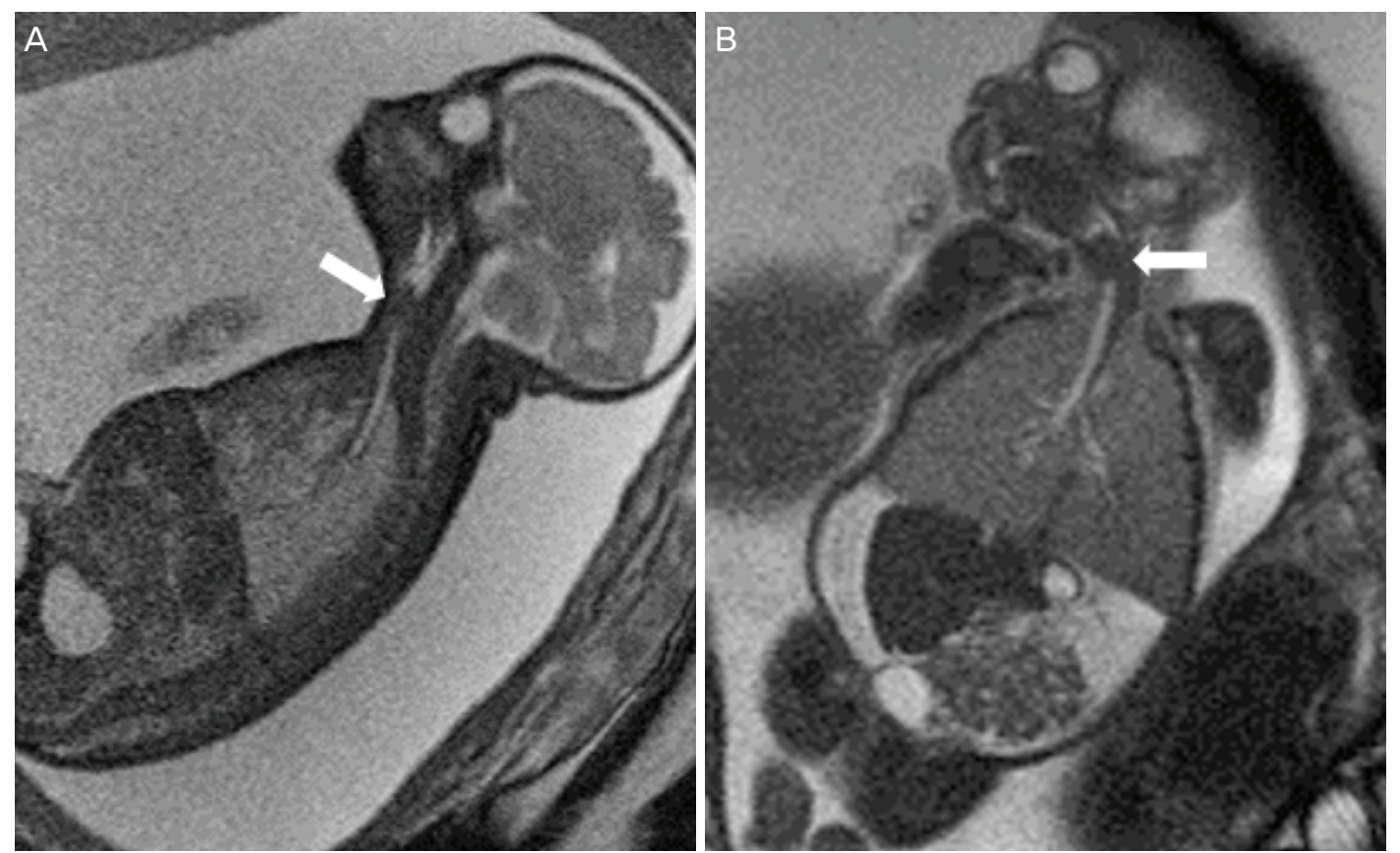

Fig. 2. Magnetic resonance imaging showing an abrupt narrowing of $T 2$ high-signal airway at the level of larynx (arrows in $A$ and $B$ ) and symmetrically enlarged both lungs (B). 


\title{
Obstetrics \& Gynecology Science
}

\author{
Vol. 64, No. 1, 2021
}

\section{Materials and methods}

We retrospectively reviewed fetuses whose prenatal diagnoses of CHAOS were postnatally confirmed at Asan Medical Center, Seoul, Korea, between 2010 and 2019. All fetuses underwent detailed high-resolution ultrasound examination, including echocardiography, during the prenatal period. They were all followed up after birth.

Prenatal data collected from the medical records of these patients included maternal age, gestational age at diagnosis, ultrasonography and MRI findings, the presence of polyhydramnios or fetal hydrops, and associated structural and chromosomal anomalies. Postnatal data included gestational age at delivery, birth weight, sex, mode of delivery, details of the EXIT procedure, peripheral oxygen saturation $\left(\mathrm{SpO}_{2}\right)$, Apgar score at one and 5 minutes, duration of follow-up, Bayley scale scores of infant development, and whether surgical correction was performed. CHAOS was diagnosed prenatally when both lungs were symmetrically enlarged with increased echogenicity (Fig. 1). Due to the enlarged lungs, the diaphragm was flattened or inverted, and the heart was anteriorly displaced (Fig. 1). MRI was performed to assess the extent of airway obstruction in fetuses with suspected CHAOS (Fig. 2).

\section{Ex utero intrapartum treatment procedure}

In 2016, we initiated the EXIT procedure after recruiting a multidisciplinary team of obstetricians, neonatologists, anesthesiologists, and otorhinolaryngologists. Under general anesthesia, the mother underwent elective cesarean section, with a Pfannenstiel incision and transverse hysterotomy of the lower uterine segment. After delivery of the fetal head and thorax, the neonatologists initially attempted fetal intubation. If that failed, the otolaryngologist immediately performed a tracheostomy. During the EXIT procedure, fetal $\mathrm{SpO}_{2}$ and heart rate were monitored, and warm saline was infused continuously into the uterus at a constant rate to prevent placental separation and umbilical cord compression. Following the tracheostomy, the umbilical cord was clamped and sectioned, and the infant was handed to the neonatologists. The placenta was then removed, and the uterus and abdominal wall were repaired layer by layer. The final diagnosis was confirmed by chest computed tomography or bronchoscopy. Brain ultrasonography was performed to

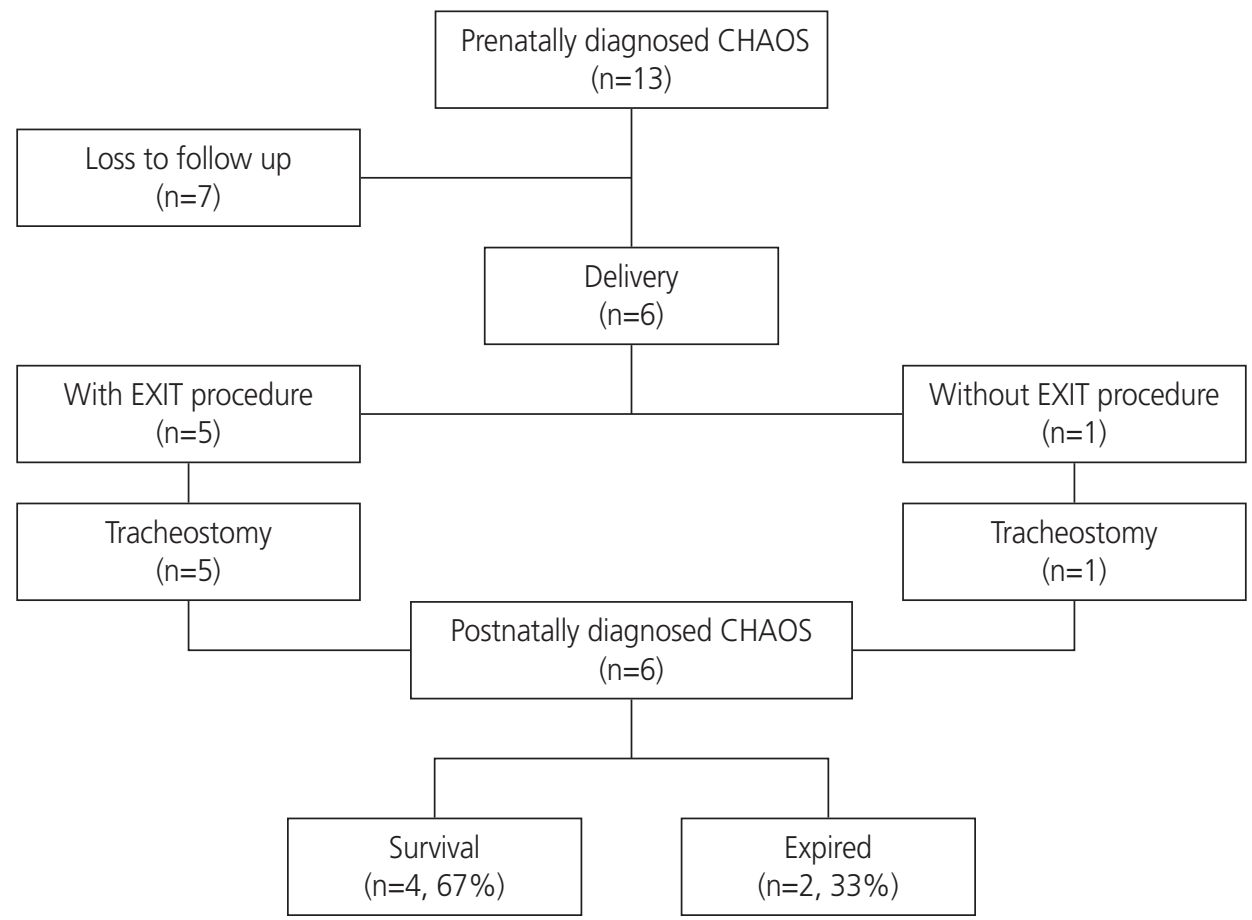

Fig. 3. Flow diagram of fetuses diagnosed with congenital high airway obstruction syndrome (CHAOS). EXIT, ex utero intrapartum treatment. 


\section{Obstetrics \& Gynecology Science}

evaluate hypoxic damage. Other associated anomalies were also evaluated. The Bayley scale scores of infant development were evaluated at an appropriate age.

\section{Statistical analysis}

Quantitative variables were expressed as medians with ranges, whereas categorical variables were expressed as frequencies and percentages.

\section{Results}

Thirteen fetuses were prenatally diagnosed with CHAOS, of whom 6 were analyzed and 7 were lost to follow-up (Fig. 3). The prenatal characteristics of the fetuses with CHAOS are shown in Table 1. The median maternal age was 32 years (range, 31-36 years), and all mothers were previously healthy. All 6 analyzed fetuses showed typical ultrasonographic findings of CHAOS at a median gestational age of 22.3 (range, 20.1-29.6) weeks. Two fetuses had congenital heart disease. Three fetuses underwent karyotyping with normal results. Due to claustrophobia, 2 women refused prenatal MRI. Of the remaining 4 fetuses who underwent prenatal $M R I$, an obstruction at the laryngeal level was suspected in 3 fetuses. One fetus (case 3) showed no remarkable abnormality of the upper airway on MRI performed at 36.4 weeks of gestation. However, the neonate was postnatally diagnosed with laryngotracheal agenesis.

The delivery details and postnatal outcomes are shown in Table 2. The median gestational age at delivery was 38.2 weeks (range, 31.0-39.5 weeks), with 1 preterm delivery at 30.2 weeks of gestation because of preterm premature rupture of membranes. The median birth weight was 2,830 $\mathrm{g}$ (range, 1,880-3,280 g), and the male-to-female ratio was 2:1. All fetuses were delivered by cesarean section with the EXIT procedure, except for case 1 in which the fetus was born before the introduction of the EXIT procedure at our institution. The duration of the EXIT procedure, including tracheostomy, was at most 13 minutes, and tracheostomy alone took at most 5 minutes.

In case 1 , intubation was attempted immediately after birth; however, it failed, and therefore tracheostomy was performed. The tracheostomy procedure lasted for $14 \mathrm{~min}$ utes. The heart rate was persistently $<60$ bpm during monitoring. Positive pressure ventilation (PPV) was performed for

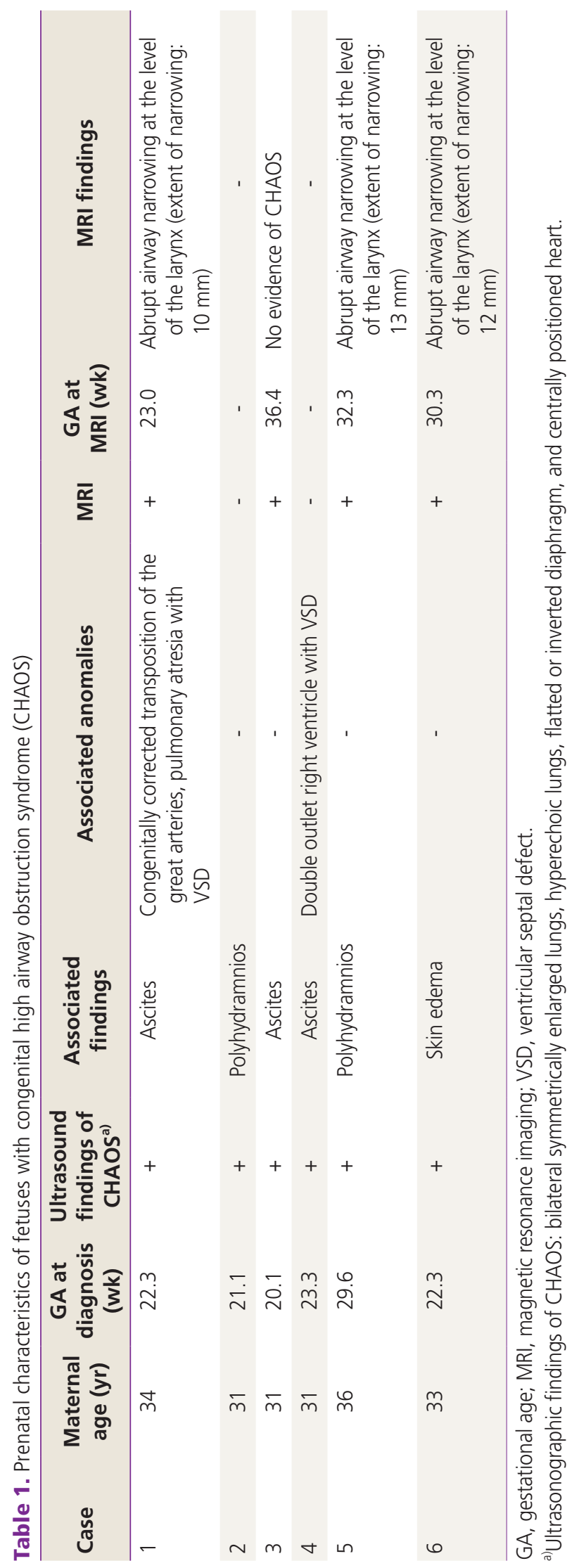




\section{Obstetrics \& Gynecology Science}

Vol. 64, No. 1, 2021

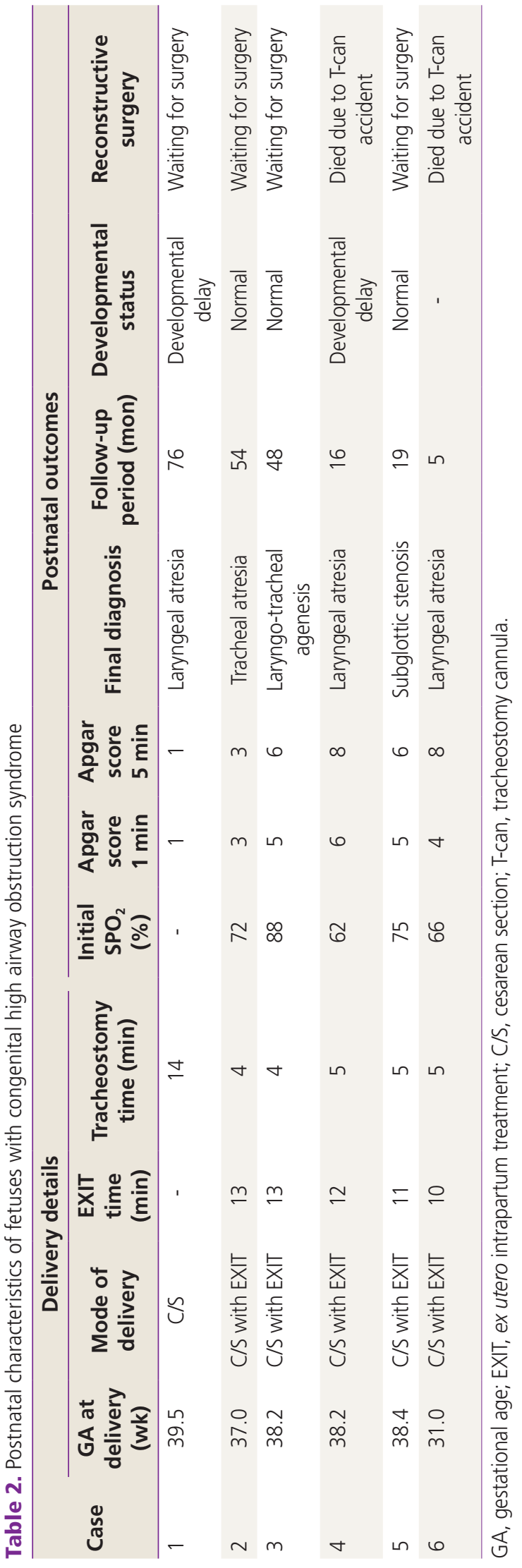

15 minutes; nonetheless, due to persistent bradycardia postPPV, cardiac massage was performed for 5 minutes, thereby stabilizing vital signs. Fortunately, no abnormal findings were noted on brain ultrasonography. The patient underwent staged repairs of congenitally corrected transposition of the great arteries, pulmonary atresia, and ventricular septal defect. The Bayley scale scores of infant development showed borderline cognitive and delayed motor developments at the age of 26 months. The patient is currently awaiting airway reconstructive surgery.

There was no evidence of hypoxic brain damage on brain ultrasound in any of the infants. Developmental testing was normal in 3 infants, except for the expressive language area. Case 4 exhibited developmental delay, but the patient had undergone several cardiac surgeries to repair a doubleoutlet right ventricle with a ventricular septal defect. On Bayley developmental testing at 15 months, his cognitive and gross motor developments corresponded to those at 10-13 months and 11-12 months of age, respectively. He died following a tracheostomy accident at 16 months of age. Another patient, case 6, also died due to a tracheostomy accident at 5 months of age when he was able to move his hands freely. The tracheostomy cannulas were self-removed during sleep. All 4 living children still require a tracheostomy without ventilator support. They are currently able to feed orally and are awaiting reconstructive surgery. Three children are now able to phonate. The patient in case 2, who had tracheal atresia, can now speak well enough to maintain a conversation.

\section{Discussion}

We found that the postnatal outcomes of fetuses prenatally diagnosed with CHAOS can be significantly improved by performing an EXIT procedure at birth. Although we did not perform an EXIT procedure in our first case, all infants were alive at birth, and those without multiple anomalies were developmentally normal at follow-up. Our experience shows that performing an EXIT procedure can secure the fetal airway while minimizing hypoxic damage to fetuses with CHAOS.

Although fetuses with CHAOS can survive after an EXIT procedure, the long-term postnatal outcomes have not been well documented so far. Previously reported cases regarding 


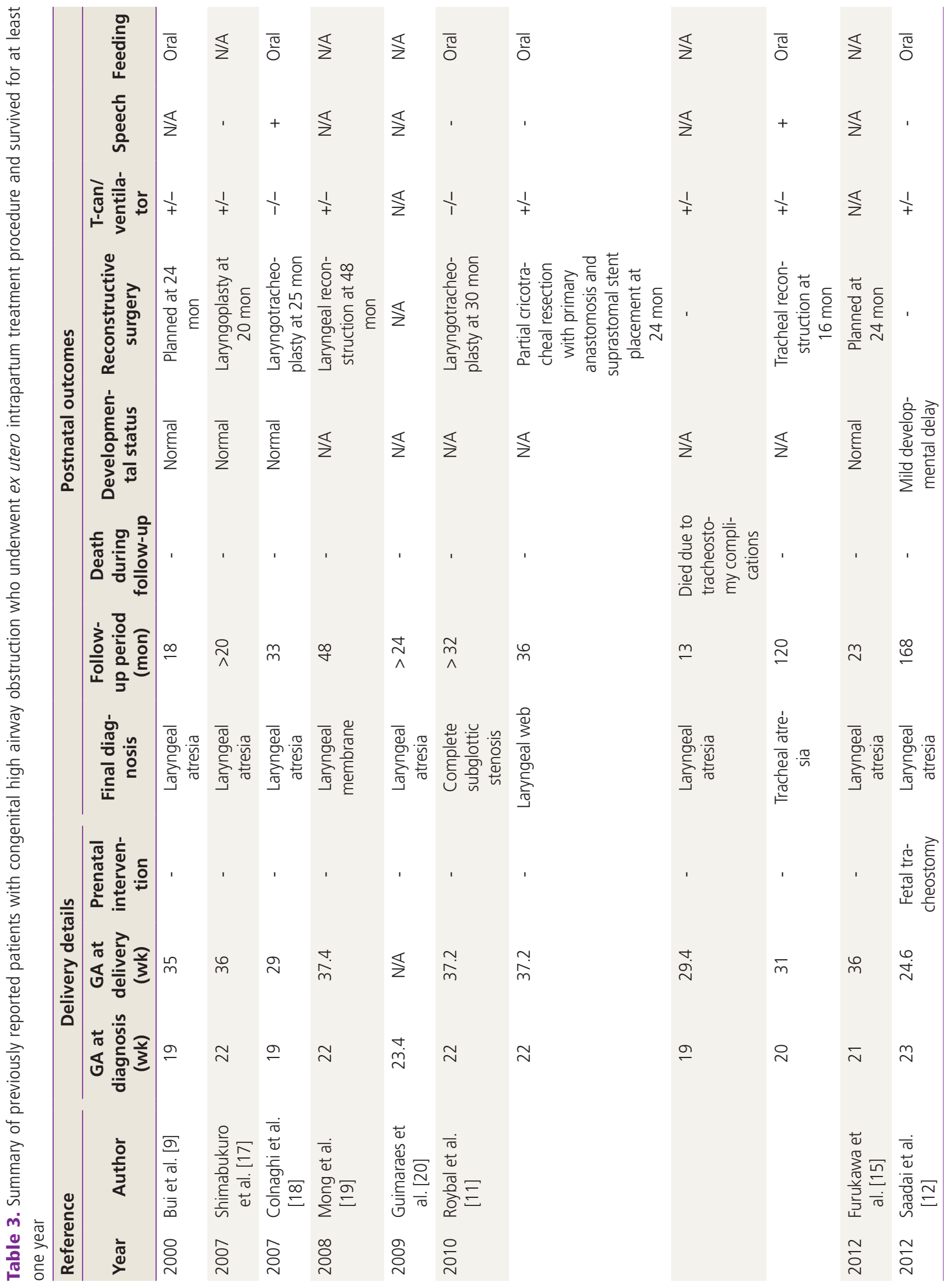




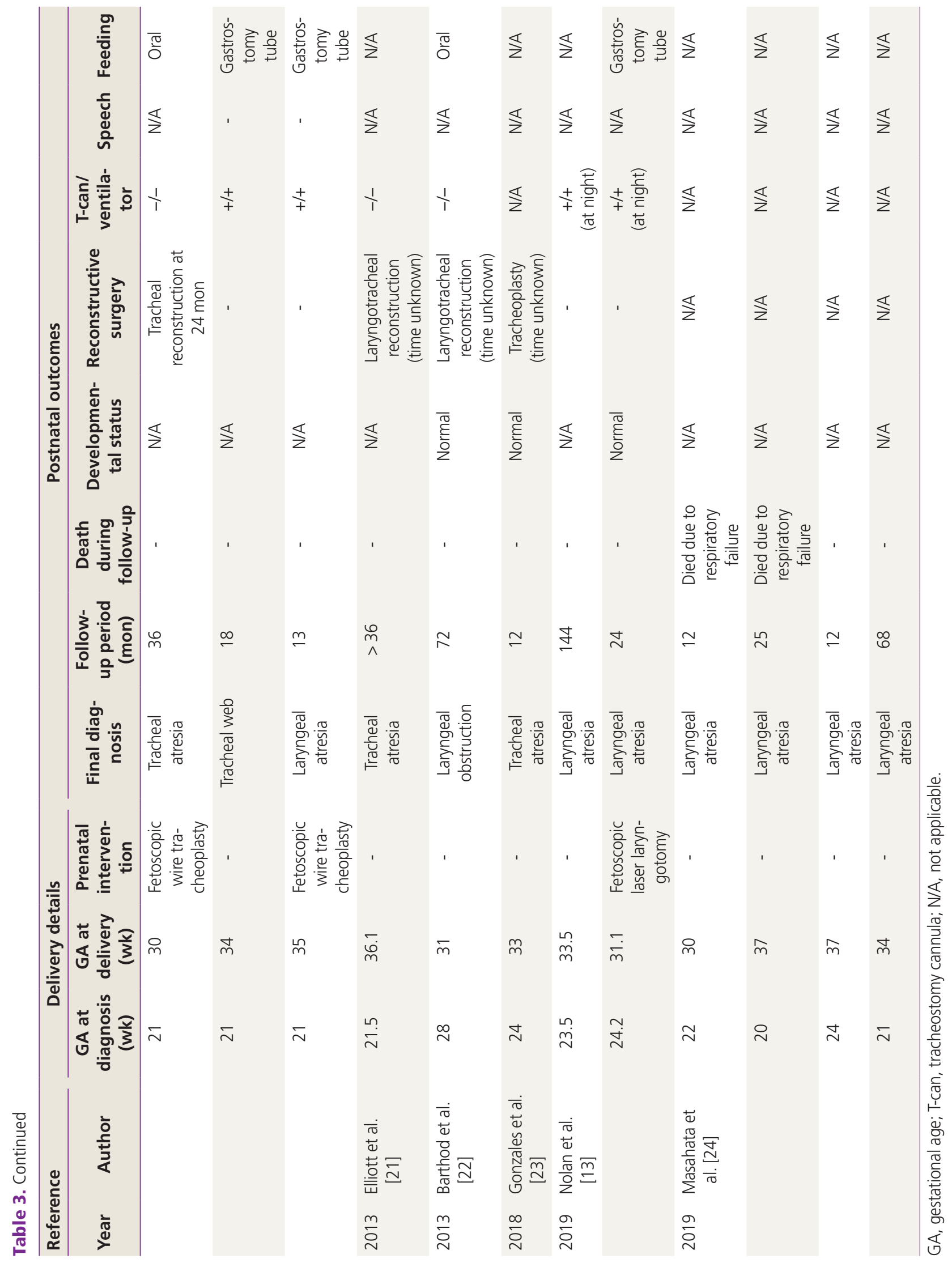




\section{Obstetrics \& Gynecology Science}

Sang-Hee Jeong, et al. Congenital high airway obstruction

the postnatal outcomes of fetuses with CHAOS who underwent the EXIT procedure with at least 12 months of followup are summarized in Table 3. Of 23 patients, 10 underwent reconstructive surgery at a median age of 24 months (range, 16-48 months). Although there is no consensus on the timing of airway reconstruction, most surgeries were carried out or planned after 24 months of age. Since reconstruction, 6 patients were able to be fed orally, but only 2 were able to speak. Of 8 patients who underwent developmental assessment, 7 were developmentally normal and only 1 had mild developmental delay. Three patients died due to respiratory complications. Similarly, in our report, 2 patients died after self-removal of the tracheostomy cannula during sleep. These tragic events highlight that respiratory complications are the most critical causes of death in children with CHAOS, and therefore thorough supervision is required following tracheostomy.

Several fetal interventions, including airway decompression via fetoscopy, have been attempted to improve the associated fetal hydrops $[12,13]$. These interventions can affect the fetus in a manner similar to a tracheoesophageal fistula. These attempts may reduce the number of fetal demises or preterm births by resolving hydrops. However, only case reports regarding the procedure itself have been published, and the overall treatment efficacy is yet to be proven. Further studies are necessary to confirm the efficacy of prenatal interventions.

Cases have been reported wherein the fetus had typical imaging findings of CHAOS during early gestation, which improved in later gestation. Kuwashima et al. [14] reported the case of a fetus who was diagnosed with CHAOS at 24 weeks of gestation with typical findings and associated hydrops on MRI. However, the findings, except for laryngeal atresia and a dilated airway, all resolved on a follow-up MRI at 35 weeks of gestation. The baby was postnatally confirmed to have a subglottic obstruction with a tiny tracheoesophageal fistula on laryngoscopy. Roybal et al. [11] also reported 3 fetuses diagnosed with CHAOS who showed improvement in imaging findings in later gestation; 2 of them were found postnatally to have a pinhole-sized opening of the airway. From previous reports, it appears that a fistula tract or small opening in the airway might cause spontaneous regression of the typical prenatal findings of CHAOS.

However, Furukawa et al. [15] suggested that an improvement of imaging findings was not always the result of fistula formation. They reported a case wherein serial MRIs were performed on a fetus with CHAOS at 22, 32, and 35 weeks of gestation. The first and the second MRls showed typical findings of CHAOS, whereas the third MRI showed improvement with no sign of a tracheoesophageal fistula. They suggested that a change in pulmonary fluid secretion and absorption resulted in decreased lung size. Case 3 in our study also showed improvement in MRI findings at 36.4 weeks of gestation, and postnatal laryngoscopy did not show any signs of a fistula or small opening, which may support the theory of Furukawa et al. [15].

We evaluated the left ventricular cardiac functions of all fetuses to determine cardiac dysfunction occurrence and the modified myocardial performance index of all fetuses was within the normal range. These findings might be explained by fetal lung expansions that were not severe enough to affect cardiac function. Moreover, none of the fetuses developed hydrops that was severe enough to cause cardiac dysfunction. To date, no cases have been published on cardiac function in fetuses with CHAOS. Therefore, future studies should focus on the evaluation of cardiac function in fetuses with CHAOS.

Complete airway obstruction is difficult to correct because the risk of restenosis is high, and bilateral vocal fold paralysis is common. Generally, an appropriate development of the normal portion of the airway is a prerequisite for successful airway reconstruction, which is performed by partial cricotracheal resection with a costal cartilage graft. The increase in the tracheal diameter and length is not always proportional to the patient's age. Thus, an adequate age for correcting CHAOS remains unestablished [16]. The enrolled patients have been scheduled to undergo airway reconstruction at 5 to 6 years of age after evaluation of airway development.

In conclusion, the proper management of CHAOS using the EXIT procedure results in a high survival rate while minimizing complications caused by hypoxemia, especially if there are no serious co-existing conditions. Therefore, an accurate prenatal diagnosis is crucial to achieve appropriate perinatal management. However, speech disorders, including expressive language, may exist even after surgical correction; thus, the infant's quality of life must be considered beforehand. Based on these investigations, appropriate information should be provided to parents for a mutual agreement with specialists on an appropriate treatment plan. 


\section{Obstetrics \& Gynecology Science}

Vol. 64, No. 1, 2021

\section{Conflict of interest}

No potential conflict of interest relevant to this article was reported.

\section{Ethical approval}

The study protocol was approved by the institutional review board of Asan Medical Center (approval number 20190423).

\section{Patient consent}

Informed consent was not required because of the retrospective nature of the study.

\section{Funding information}

None.

\section{References}

1. Hedrick MH, Ferro MM, Filly RA, Flake AW, Harrison MR, Adzick NS. Congenital high airway obstruction syndrome (CHAOS): a potential for perinatal intervention. J Pediatr Surg 1994;29:271-4.

2. Lim FY, Crombleholme TM, Hedrick HL, Flake AW, Johnson MP, Howell LJ, et al. Congenital high airway obstruction syndrome: natural history and management. J Pediatr Surg 2003;38:940-5.

3. Oepkes D, Teunissen AK, Van De Velde M, Devlieger H, Delaere $\mathrm{P}$, Deprest J. Congenital high airway obstruction syndrome successfully managed with ex-utero intrapartum treatment. Ultrasound Obstet Gynecol 2003;22:437-9.

4. Joshi P, Satija L, George R, Chatterjee S, D'Souza J, Raheem $A$. Congenital high airway obstruction syndromeantenatal diagnosis of a rare case of airway obstruction using multimodality imaging. Med J Armed Forces India 2012;68:78-80.

5. Hirose S, Farmer DL, Lee H, Nobuhara KK, Harrison MR.
The ex utero intrapartum treatment procedure: Looking back at the EXIT. J Pediatr Surg 2004;39:375-80.

6. Paek BW, Callen PW, Kitterman J, Feldstein VA, Farrell J, Harrison MR, et al. Successful fetal intervention for congenital high airway obstruction syndrome. Fetal Diagn Ther 2002;17:272-6.

7. Bouchard S, Johnson MP, Flake AW, Howell LJ, Myers LB, Adzick NS, et al. The EXIT procedure: experience and outcome in 31 cases. J Pediatr Surg 2002;37:418-26.

8. Crombleholme TM, Sylvester K, Flake AW, Adzick NS. Salvage of a fetus with congenital high airway obstruction syndrome by ex utero intrapartum treatment (EXIT) procedure. Fetal Diagn Ther 2000;15:280-2.

9. Bui TH, Grunewald C, Frenckner B, Kuylenstierna R, Dahlgren G, Edner A, et al. Successful EXIT (ex utero intrapartum treatment) procedure in a fetus diagnosed prenatally with congenital high-airway obstruction syndrome due to laryngeal atresia. Eur J Pediatr Surg 2000;10:328-33.

10. DeCou JM, Jones DC, Jacobs HD, Touloukian RJ. Successful ex utero intrapartum treatment (EXIT) procedure for congenital high airway obstruction syndrome (CHAOS) owing to laryngeal atresia. J Pediatr Surg 1998;33:1563-5.

11. Roybal JL, Liechty KW, Hedrick HL, Bebbington MW, Johnson MP, Coleman BG, et al. Predicting the severity of congenital high airway obstruction syndrome. J Pediatr Surg 2010;45:1633-9.

12. Saadai $P$, Jelin EB, Nijagal A, Schecter SC, Hirose $S$, MacKenzie TC, et al. Long-term outcomes after fetal therapy for congenital high airway obstructive syndrome. J Pediatr Surg 2012;47:1095-100.

13. Nolan HR, Gurria J, Peiro JL, Tabbah S, Diaz-Primera R, Polzin W, et al. Congenital high airway obstruction syndrome (CHAOS): Natural history, prenatal management strategies, and outcomes at a single comprehensive fetal center. J Pediatr Surg 2019;54:1153-8.

14. Kuwashima S, Kitajima K, Kaji Y, Watanabe H, Watabe Y, Suzumura H. MR imaging appearance of laryngeal atresia (congenital high airway obstruction syndrome): unique course in a fetus. Pediatr Radiol 2008;38:344-7.

15. Furukawa R, Aihara T, Tazuke Y, Maeda K, Kuwata T. Congenital high airway obstruction syndrome without tracheoesophageal fistula and with in utero decrease in relative lung size. Pediatr Radiol 2012;42:1510-3. 


\section{Obstetrics \& Gynecology Science}

Sang-Hee Jeong, et al. Congenital high airway obstruction

16. Hartnick CJ, Rutter M, Lang F, Willging JP, Cotton RT. Congenital high airway obstruction syndrome and airway reconstruction: an evolving paradigm. Arch Otolaryngol Head Neck Surg 2002;128:567-70.

17. Shimabukuro F, Sakumoto K, Masamoto H, Asato $Y$, Yoshida T, Shinhama A, et al. A case of congenital high airway obstruction syndrome managed by ex utero intrapartum treatment: case report and review of the literature. Am J Perinatol 2007;24:197-201.

18. Colnaghi M, Condo V, Gagliardi L, Mirabile L, Fumagalli M, Mosca F. Prenatal diagnosis and postnatal management of congenital laryngeal atresia in a preterm infant. Ultrasound Obstet Gynecol 2007;29:583-5.

19. Mong A, Johnson AM, Kramer SS, Coleman BG, Hedrick $\mathrm{HL}$, Kreiger $\mathrm{P}$, et al. Congenital high airway obstruction syndrome: MR/US findings, effect on management, and outcome. Pediatr Radiol 2008;38:1171-9.

20. Guimaraes CV, Linam LE, Kline-Fath BM, Donnelly LF, Calvo-Garcia MA, Rubio El, et al. Prenatal MRI findings of fetuses with congenital high airway obstruction sequence. Korean J Radiol 2009;10:129-34.

21. Elliott R, Vallera C, Heitmiller ES, Isaac G, Lee M, Crino $J$, et al. Ex utero intrapartum treatment procedure for management of congenital high airway obstruction syndrome in a vertex/breech twin gestation. Int J Pediatr Otorhinolaryngol 2013;77:439-42.

22. Barthod G, Teissier N, Bellarbi N, Viala P, Oury JF, Dray $G$, et al. Fetal airway management on placental support: limitations and ethical considerations in seven cases. J Obstet Gynaecol 2013;33:787-94.

23. Gonzales SK, Goudy S, Prickett K, Ellis J. EXIT (ex utero intrapartum treatment) in a growth restricted fetus with tracheal atresia. Int J Pediatr Otorhinolaryngol 2018;105:72-4.

24. Masahata K, Soh H, Tachibana K, Sasahara J, Hirose M, Yamanishi $T$, et al. Clinical outcomes of ex utero intrapartum treatment for fetal airway obstruction. Pediatr Surg Int 2019;35:835-43. 